\title{
Is There a Purpose in the Biological Evolution of Living Beings?
}

Justo Aznar, MD

\begin{abstract}
An unquestionably important biological question is whether human beings are the product of chance or of purpose in the evolutionary process. Charles Darwin did not accept purpose in biological evolution, a view not shared by his colleague Alfred Russel Wallace. The controversy has remained ever since, and while many experts argue against purpose in biological evolution, many others defend it. This paper reflects on this biological and ethical problem, relating it to the possible existence of a plan that governs and shapes the evolution of living beings and that is ultimately responsible for the development of Homo sapiens. National Catholic Bioethics Quarterly 19.3 (Autumn 2019): 000-000.
\end{abstract}

The dialogue between science and faith remains vigorous in the second decade of the twenty-first century. An important goal of this ongoing discussion is to assess whether human beings, and nature in general, rely on a higher intelligence for their creation and continued existence. In fact the fundamental issues in the dialogue between science and faith ultimately address the role that the existence of God plays in nature. These issues are (1) the origin of the universe, or in a broader conception, cosmology; (2) everything related to the science of evolution and its ideological drift-evolutionism-

Justo Aznar, MD, PhD, is the director of the Life Sciences Institute at the Catholic University of Valencia in Spain. The author thanks Ester Bosch for her collaboration on this work.

The views expressed in the $N C B Q$ do not necessarily represent those of the editor, the editorial board, the ethicists, or the staff of The National Catholic Bioethics Center.

The analysis in this paper draws on the history of evolutionary theory presented in Stephen L. Talbott, "Evolution and the Purpose of Life," New Atlantis no. 51 (Winter 2017): 63-91. 
especially whether human beings are a random product of that process; (3) the need to reconcile original sin with the new biological concepts on the origin of the human species; (4) the existence of evil in the world, especially moral evil; and (5) everything related to what has come to be called enhancement of the human condition, especially posthumanism, which ultimately tries to produce beings stripped of their own human nature by distorting and accelerating the evolutionary process.

This paper focuses on biological evolution and evolutionism, in particular on the possible existence of teleology in that evolutionary process.

\section{Traditional Theories of Biological Evolution}

Biological evolution must answer two challenging principal questions: First, how does the evolutionary process explain the origin of matter? Second, how does evolution explain the development of human consciousness from matter? This transition clearly requires an ontological leap that is not explainable as a simple evolution of matter resulting from chance: "Matter, however much it is developed, cannot produce a single thought, nor can it understand itself." To understand how evolutionary theory addresses these concerns, we must look at its historical development.

\section{Charles Darwin}

Charles Darwin is the father of the theory that natural selection is the key to the entire evolutionary process of living beings. In his 1859 book On the Origin of Species, he states a simple version of the concept that would later be referred to as Darwinian evolution: "Descent with modification through natural selection," where natural selection refers to the "preservation of favourable variations and the rejection of injurious variations." ${ }^{2}$ Under this theory, the fittest prevail, and the weakest are eliminated.

\section{Alfred Russel Wallace}

Another prominent figure in the field of biological evolution was Alfred Russel Wallace, who held a view contrary to Darwin's regarding the mechanisms of human evolution. Wallace argued that natural selection does not seem sufficient to explain the origin of the human species, so a nonmaterial agent must have intervened in its genesis. According to him, humans would not have become what they are if only natural selection were taken into account, given that this process promotes only useful traits. Thus, in his opinion, human evolution required a certain divine intervention to get where it is today. ${ }^{3}$

1. Alfonso Aguiló, “Evolución: Bien ¿pero dónde?,” Fluvium, accessed October 28, 2019, http://www.fluvium.org/textos/etica/eti944.htm. All translations are the author's unless otherwise stated.

2. Charles Darwin, On the Origins of Species (London: John Murray, 1859), chaps. 4, 14, Project Gutenberg, https://www.gutenberg.org/files/1228/1228-h/1228-h.htm.

3. Andrew Berry, "Wallace, el evolucionista radical," Investigación y ciencia no. 445 (October 2013): 41. 


\section{Modern Synthesis}

From the 1920 s to the 1960 s, a set of unified principles was developed for evolutionary theory, which gave rise to what has come to be called a modern synthesis. ${ }^{4}$ This model provides the theoretical framework for current evolutionary biology. It brings together the contributions of experimental genetic studies, the theory of population genetics, and natural, systematic, paleontological, and ecological population studies. It concludes that evolution is the result of the interaction of two main forces of different natures: mutation, which generates a new genetic and phenotypic variation, and natural selection.

The ideas at the core of modern synthesis are that (1) evolution at all levels results from continuous changes in populations as described by population genetics; ${ }^{5}$ (2) genetic mutation is the result of random processes - that is, in control processes or systems, mutations do not occur in a way that benefits the organisms; and (3) the main influence that directs the evolution of the organism is natural selection, which is not subject to any control process or system either. Without doubt modern synthesis is essentially defined by its assertion that there is no mechanism of purpose behind the selection itself. This is supported by Richard Dawkins, who says that the modern synthesis of evolution is a mechanistic theory of population genetics and random mutation that excludes all purpose. ${ }^{6}$ This opinion is shared by Jacques Monod, who explains that "the universe was not pregnant with life nor the biosphere with man. Our number came up in the Monte Carlo game."

\section{Synthetic Theory of Evolution}

Evolutionary theory was redefined in 1930, combining the concept of Darwinian natural selection with that of Mendelian inheritance. This theory was developed especially by Theodosius Dobzhansky, "who with a master hand synthesised population genetics and data on the variation and genetic differences between species." Dobzhansky joined Ernest Mayr and George Simpson to definitively articulate the synthetic theory of evolution. In the opinion of Mariano Artigas and Daniel Turbón, their model is characterized by the interrelationship of five different factors: (1) mutation, or random change in DNA; (2) genetic recombination of DNA; (3) genetic drift, or random change in the frequency of genetic variants, from one generation to another when the population is small; (4) migration, which incorporates individual carriers

4. Jonathan Bartlett, "Evolutionary Teleonomy as a Unifying Principle for the Extended Evolutionary Synthesis," Bio-complexity 2017.2 (November 27, 2017): 1-7, doi: 10.5048 /BIO-C.2017.2.c.

5. Douglas J. Futuyma, "Can Modern Evolutionary Theory Explain Macroevolution?," in Macroevolution: Explanation, Interpretation and Evidence, ed. Emanuele Serrelli and Nathalie Gontier (Cham, Switzerland: Springer, 2015), 29-86.

6. Richard Dawkins, The Selfish Gene, 4th ed. (Oxford: Oxford University Press, 2016).

7. Jacques Monod, Chance and Necessity: An Essay on the Natural Philosophy of Modern Biology (New York: Vintage, 1971), 146.

8. Mariano Artigas and Daniel Borrega Turbón, El origen del hombre: Ciencia, filosofia y religión (Pamplona: EUNSA, 2007): 47. 
of different genetic variations in the reproductive group; and (5) natural selection, or differential reproduction of some organisms over others, caused by the environment. In this theory, as in Darwin's, evolution occurs through the slow and inexorable accumulation of small variations caused by the aforementioned mechanisms.

\section{Punctuated Equilibrium}

This theory of the slow accumulation of mutations was opposed in the 1970s, in particular by Stephen Jay Gould, who proposed an alternative: the punctuated equilibrium theory. On this view the emergence of the main lineages of living organisms occurred abruptly or in leaps. Certainly, after such leaps there may have been periods - even very long ones — of relative equilibrium and slow evolution.

\section{Extended Evolutionary Synthesis}

However, in the last decade the need to rethink the modern synthesis of biological evolution has arisen, and the extended evolutionary synthesis proposed by Massimo Pigliucci and Gerd Müller in 2010 has been gaining momentum. ${ }^{9}$ A fundamental characteristic in the change from modern synthesis to extended evolutionary synthesis is the inclusion of purpose in evolutionary processes, which requires the existence of a plan in them, something that was not considered in the Darwinian theory of evolution.

According to Jonathan Bartlett extended synthesis is characterized basically by (1) "contingency as a more primary actor in determining possible mutations"; (2) "shifting focus from individual genes to gene networks"; (3) "various new kinds of inheritance, including transgenerational epigenetic inheritance, niche inheritance, and cultural inheritance"; (4) "the influence of developmental biology on the theory of evolution"; and (5) "the analysis of evolvability itself." 10

This interpretation is supported by a 1968 article by Japanese geneticist Motoo Kimura, in which he expounded his neutral theory of biological evolution. He tried to explain the changes produced in the genome over time, which eventually gave rise to the evolution of the species of living beings. Antonio Barbadilla and colleagues summarize his conclusion: "A large part of the genetic variation observed in populations and between species is due to the fluctuation and random fixation in the genome of neutral genetic variants. The fact that a variant is neutral does not mean that it lacks biological function, but that it is equivalent to others in the face of natural selection. ... When two or more variants are neutral, they are equally effective for the survival and reproduction of the individual. The appearance by mutation of a neutral variant is undetectable for selection and only chance will determine its survival or extinction." 11

9. Massimo Pigliucci and Gerd B. Müller, eds., Evolution, the Extended Synthesis (Cambridge, MA: MIT Press, 2010).

10. Bartlett, "Evolutionary Teleonomy," 2.

11. Antonio Barbadilla, Sònia Casillas, and Alfredo Ruiz, "La teoría neutralista de la evolución molecular, medio siglo después," Investigación y ciencia no. 509 (February 2019): 
In 1983 Kimura wrote The Neutral Theory of Molecular Evolution, which "contributed decisively to the establishment of the neutral theory as a paradigm of molecular evolution." 12

\section{Chance, Perspective, and Purpose}

As already mentioned, Darwin proposed that chance plays a decisive role in the evolutionary process. Essentially, evolutionary changes happen exclusively through the concurrence of independent causal lines. At a symposium hosted by Pope Benedict XVI, Peter Schuster explained what chance means in this context: "There are by far fewer investigations, if any at all, into the 'chance' in the expressions 'chance variations,' or simply into 'chance.' Most often biologists speak as though everyone understood what is meant by chance. Chance, for biologists, seems to mean ultimately: arbitrary causes, first these, then those, but in any case always the absence of any sort of plan or design, of any goal-oriented activity and intention. This is considered to be downright axiomatic." 13

However, it should be remembered that chance exists only for human beings, who are ignorant of some of the causes that concur in the realization of an event. The concept of chance does not exist for God, ${ }^{14}$ who is aware of all the causal elements that occur to reach an end. Consequently, He is aware of the final result of those actions. Chance is necessary only when considering evolution from the perspective of contingent beings such as ourselves. However, there is no chance from the perspective of an omniscient being who has knowledge of all causes. Therefore, considering chance as an element that defines biological evolution does not exclude divine action. If God acts through secondary causes, which appear to be chance from our perspective, then it is intelligible to posit purpose in evolution. ${ }^{15}$

\section{Teleological Evolution}

The possibility of purpose in evolution is articulated in teleological evolution. Francisco Ayala provides a succinct description of this theory: "Evolution can also be considered as a natural process through which God brings living species into existence in accordance with His own plan." Ayala goes on to explain that this is in line with the opinion of Artigas and Turbón, who argue that "the combination of

52-59; and Motoo Kimura, "Evolutionary Rate at the Molecular Level," Nature 217.5129 (February 17, 1968): 624-626, doi: 10.1038/217624a0.

12. Barbadilla et al., "La teoría neutralista," 52-59; and Motoo Kimura, The Neutral Theory of Molecular Evolution (Cambridge, UK: Cambridge University Press, 1983).

13. Peter Schuster, "Evolution and Design: A Review of the State of the Art in the Theory of Evolution," in Creation and Evolution: A Conference with Pope Benedict XVI in Castel Gandolfo (San Francisco: Ignatius Press, 2008), 55.

14. See, for example, Keith Ward, God, Chance and Necessity (Oxford: Oneworld, 1996).

15. Such an argument depends on the truth of the following claims: (1) God exists, (2) God is omniscient, (3) God acts through secondary causality, and (4) this introduces purpose. 
chance and necessity, variation and selection, together with the potentialities for self-organisation, can be easily contemplated as the path used by God to promote the process of evolution." 16

Similarly, Héctor Velázquez says that we cannot discard the inclusion of teleological mechanisms in the development of living beings toward an end. Likewise, teleology makes reference to the fact that there are directionality, cooperativity, and functionality in living beings: even the "behaviours of the individual cells in our bodies are, in a certain sense, intelligent and deliberate, directed knowingly towards ends that satisfy their needs, so that the existence of a purpose or project is essential for the very definition of living beings." This enables us to say that "there is purpose and teleology at the level of every individual organisms." ${ }^{17}$

However, these teleological proposals have been - and still are-widely contested by leading evolutionary biologists, who are opposed to including the concept of purpose in biological evolutionary processes. As Luis Alonso contends, "One of the aims of logical empiricism was to eradicate the final cause from the field of meta-science. Philosophers and scientists have remained committed to that work, particularly in the domain of biology," ${ }^{18}$ which "is supposed to remain free of teleology, as a computer is supposed to remain virus-free." 19

Thus Dawkins says that "the theory of natural selection provides a mechanistic, causal account of how living things came to look as if they had been designed for a purpose." ${ }^{20}$ Likewise, Gould says that humans are not the result of an evolution directed toward their appearance on earth, but that evolution is a sum of contingencies: a process in which chance plays a fundamental role. Hence evolution is essentially an unpredictable process: "Humans arose, rather, as a fortuitous and contingent outcome of thousands of linked events, any one of which could have occurred differently and sent history on an alternative pathway that would not have led to consciousness." 21

Nevertheless, it seems evident that all biological activity, even at the molecular level, seems to be intentional and targeted. Everything seems to lead toward the fulfillment of the obvious purposes of the organism. Robert Trivers states that "even the humblest creature, say, a virus, appears organized to do something; it acts as if

16. Francisco J. Ayala, La teoría de la evolución. De Darwin a los últimos avances de la genética (Madrid: Temas de Hoy Madrid, 1994), 106, 147.

17. Héctor Velázquez Fernández, "Naturaleza y finalidad," Investigación y ciencia no. 464 (May 2015): 50-51.

18. Luis Alonso, "Ciencia y teleología," Investigación y ciencia no. 507 (December 2018): 91-92. See also Michael Ruse, On Purpose (Princeton, NJ: Princeton University Press, 2018).

19. Schuster, "Evolution and Design," 55.

20. Richard Dawkins, "Replicators and Vehicles," in Current Problems in Sociobiology, ed. Kings College Sociobiology Group (Cambridge, UK: Cambridge University Press, 1982), 45.

21. Stephen Jay Gould, "La evolución de la vida en la tierra," Investigación y ciencia no. 219 (December 1994): 54-61. 
it is trying to achieve some purpose." 22 Larry Arnhart holds that "Darwin's biology does not deny - rather, it reaffirms - the immanent teleology displayed in the striving of each living being to fulfil its specific ends.... Reproduction, growth, feeding, healing, courtship, parental care for the young - these and many other activities of organisms are goal-directed." 23

Evolution tends toward "increasing complexity," which we clearly observe but cannot explain. Biology can describe the phenomenon, but philosophy of nature and metaphysics are required to describe how it occurs. ${ }^{24}$ These observations raise the question, Does teleology require the existence of a higher intelligence? In answer, Artigas says that such a being must exist as the primary cause of physical existence, a being who directs but does not determine nature. The divine plan then is realized through creativity, contingency, and chance at the natural, species, and individual levels. ${ }^{25}$

\section{Teleonomic Evolution}

In 1958 Colin Pittendrigh introduced the term teleonomy to replace teleology and thereby to avoid the need to accept the action of a higher intelligence in the evolutionary process of living things ${ }^{26}$ This essentially refers to the fact that the possible plan that will direct the development of natural phenomena is included in the structure of the system itself. ${ }^{27}$ Mayr supported this concept shortly thereafter. ${ }^{28}$

According to Bartlett, the concept of teleonomy refers to two fundamental facts: (1) "Organisms exhibit purposiveness because of teleonomy," and (2) "evolution lacks any teleonomic driver." ${ }^{29}$ For him teleonomy seems to play a central, unifying role in the extended evolutionary synthesis.

Stephen Talbott summarizes E. S. Russell's observation that animal behavior indicates an intrinsic self-directedness, which is not explainable by mechanistic theories alone:

The instinctiveness of the animal's behaviour does not make it merely mechanistic, directed only by "the physical and chemical stimuli impinging upon the sense organs of the animal." Not even "mechanical" reflexes can be understood

22. Robert Trivers, Social Evolution (Menlo Park, CA: Benjamin-Cummings, 1985), 5, original emphasis.

23. Larry Arnhart, Darwinian Natural Right: The Biological Ethics of Human Nature (Albany, NY: State University of New York Press, 1998), 245.

24. Rafael Jordana, La ciencia en el horizonte de una razón ampliada. La evolución y el hombre a la luz de las ciencias biológicas y metabólicas (Madrid: Unión Editorial, 2016), 150.

25. Mariano Artigas, Ciencia y religión. Conceptos fundamentales (Pamplona: EUNSA, 2007), 42-46, 68.

26. C. S. Pittendrigh, "Adaptation, Natural Selection, and Behavior," in Behavior and Evolution, ed. Anne Roe and George Gaylord Simpson (New Haven, CT: Yale University Press, 1958), 390-416.

27. Ayala, Teoría de la evolución, 147.

28. Ernst Mayr, "Cause and Effect in Biology," Science 134.3489 (November 10, 1961): 1501-1506.

29. Bartlett, "Evolutionary Teleonomy," 4. 
in merely mechanical terms: "There is no such thing as pure reflex action in normal behaviour; all so-called reflexes are parts of co-ordinated and generally 'purposive' or directive actions, and they cannot be understood until their relation to the objective aim of the whole action is known."... Such behaviour shows us, as Russell puts it, that "the end is more constant than the means of attaining it." ... It requires an active intelligence capable of improvising responses within an infinite variety of unforeseeable circumstances in order for the end to be achieved. ${ }^{30}$

In January 2019 the journal Science published an interesting study that analyzed the genome of one hundred fifty Icelanders. The authors claim that they compiled the most detailed map of the human genome to date. Thirty-five genomic variants were identified that affect the rate of genetic recombinations. The study also showed that new mutations were fifty times more likely where the paternal and maternal chromatid crossovers occured than at recombination sites elsewhere on the genome. ${ }^{31}$

Summarizing the relationship between teleology and teleonomy, Velázquez says that teleonomy and teleology can be reconciled through secondary causality. The tendentiality and finite purposes observable in nature are the secondary causes through which "an invaluable materialised rationality" operates toward an overarching final goal. ${ }^{32}$ This underlying teleology is enigmatic to beings inside the system, especially since they cannot ask the creative intelligence behind the system about its purpose. It seems that the concept of teleonomy is widely accepted. Even Monod, the primary proponent of chance in evolutionary processes, dedicated extensive sections of Chance and Necessity to a reflection on teleonomy.

\section{Biological Altruism}

In the context of evolutionary biology, biological altruism can be defined as an organism's behavior that "benefits other organisms at a cost to itself, [whereby it] reduces the number of offspring it is likely to produce itself, but boosts the number that other organisms are likely to produce." 33 This concept is directly related to the concept of reproductive fitness. Common examples include insects that care for a queen but do not reproduce on their own and birds that help protect and feed other birds' chicks. ${ }^{34}$ Explaining altruism is a fundamental problem for evolutionary biology.

30. Stephen L. Talbott, "Evolution and the Purpose of Life," New Atlantis no. 51 (Winter 2017): 67, 68, citing E. S. Russell, original emphasis.

31. Bjarni V. Halldorsson et al., "Characterizing Mutagenic Effects of Recombination through a Sequence-Level Genetic Map,” Science 363.6425 (January 25, 2019): 1-10, doi: 10.1126/science.aau1043.

32. Héctor Velázquez Fernández, private message to author, February 21, 2019.

33. Samir Okasha, "Biological Altruism," in Stanford Encyclopedia of Philosophy, ed. Edward N. Zalta, revised July 21, 2013, https://plato.stanford.edu/entries/altruism-biological/.

34. Ibid. See also Jacobus J. Boomsma, "Kin Selection versus Sexual Selection: Why the Ends Do Not Meet," Current Biology 17.16 (August 21, 2007): R673-R683, doi: 10.1016/j .cub.2007.06.033; Charlie K. Cornwallis et al., "Promiscuity and the Evolutionary Transition to Complex Societies," Nature 466.7309 (August 19, 2010): 969-972, doi: 10.1038/nature09335; and Ben J. Hatchwell, Philippa R. Gullett, and Mark J. Adams, "Helping in Cooperatively 
Given the Darwinian idea of survival of the fittest, how can we explain individuals' engaging in a behavior that reduces their own fitness, while increasing that of others? ${ }^{35}$

Typically, biological altruism describes conscious and unconscious social behavior. However, there is some indication that it can occur at the genetic and cellular levels as well. For example, in the progression from unicellular to multicellular organisms, some cells "removed" themselves from the germline "to specialize in various survivalrelated functions." This change indicates "an adaptive strategy to enhance survival at an immediate cost to reproduction." "Im Importantly, this indicates that biological altruism may be operative in various functional and develomental contexts.

Nevertheless, biological altruism undeniably seems to be present in some biological processes. One notable aspect of nonhuman animal reproduction is the apparent passivity of the female in coitus. It seems that her attitude is simply to remain motionless to enable her to be mounted by the male. ${ }^{37}$ This is in clear contrast with the active participation of the female in human coitus, especially in sharing sexual pleasure with the male. It is surprising that in the evolutionary process of mammals, there is such a marked difference in the physiological reproductive mechanism between nonrational and rational mammals, even among species as close as irrational hominids and Homo sapiens. One may ask what is the telos, or purpose, of this evolutionary process. It could be a mechanism aimed at ensuring the continuation of the species, because it is easy to assume the difficulties to which that continuation would be subject if a human woman were not encouraged to participate in the reproductive act by enjoying a sexual pleasure as intense as that of the male.

Given the association between teleonomy and teleology described above, could a form of somatic biological altruism be the secondary cause in a teleological plan, which would not be indicated by the environment, let alone conceivable, when the evolutionary change occurred? A possible example may be related to the existence of periods of infertility in the female reproductive cycle among humans. There appears to be little doubt that during the entire evolutionary period of the human species, the demographic circumstances have changed substantially. In fact it can be said that in its initial stages, and during almost all the years of its evolutionary development until the mid-twentieth century, there was no risk of excessive demographic growth of our species. Thus women having periods of infertility within their reproductive cycle would not have an explicit purpose. The more births, the better to maintain the species. Why do these periods of infertility exist? Why has evolution created them?

Breedding Long-Tailed Tits: A Test of Hamilton's Rule," Philosophical Transactions of the Royal Society of London. Series B, Biological Sciences 369.1642 (May 19, 2014): 1-9, doi: 10.1098/rstb.2013.0565.

35. Asher Leeks and Stuart West, “Altruism in a Virus," Nature Microbiology 4.6 (June 2019): 910-911, doi: 10.1038/s41564-019-0463-0.

36. Aurora M. Nedelcu and Richard E. Michod, "The Evolutionary Origin of an Altruistic Gene," Molecular Biology and Evolution 23.8 (August 2006): 1460, doi: org/10.1093 /molbev/msl016.

37. L. S. Katz and T. J. McDonald, "Sexual Behavior of Farm Animals," Theriogenology 38.2 (August 1992): 239-253, doi: 10.1016/0093-691X(92)90233-H. 
Could this have any relation to an altruistic end not related to reproductive fitness? Could it be aimed at resolving demographic needs that could present at a certain time in the evolution of the species?

Since the mid-twentieth century, perhaps prompted by the decline in mortality (especially infant mortality), the lengthening of the average life span, and other factors, the possibility has been raised that there is excessive growth of the human population. Therefore, the fact that women have a period of infertility within their reproductive cycle could be useful to regulate that hypothetical excessive growth of the human species, because those periods of infertility could be useful to space, or even suppress, the birth of more individuals of the species. But if this biological circumstance, which may now be convenient and even necessary, were not programmed throughout the evolutionary period of the human species, it could not occur now.

That is, a biological condition - the cyclical infertility of women - that may be useful at present had to be programmed from the start of the Homo sapiens species and develop throughout its evolutionary process. It was started and perpetuated at a time when it was clearly not necessary, so that it could be applied at this time. This evolutionary process that has propitiated the existence of periods of infertility within the reproductive cycle of women could be another example of biological altruism.

\section{Evolution and Creation in the Confines of Knowledge}

Certainly, one important aspect of the dialogue between science and faith with respect to biological evolution is whether there is a teleological component of evolutionary processes. In addition, does a higher intelligence govern it or, at least, imprint it on the very nature of living beings?

Alejandro Llano sums up the topic superbly:

If there is a cosmological and biological evolution with sense, in order to explain it radically, i.e. metaphysically, it must be referred to a creative intelligence. And, in turn, this creative intelligence, although it has created the world freely, must have created a world ordered to an end and, therefore, purposeful. What really exists is creation as a stable metaphysical condition of material things that evolve precisely because they have been created with sense and purpose and are, therefore, guided by a wise ordering providence.

The basic conceptual failure common to both radical views is forgetting the teleological nature of the physical world. According to this finalist conception, the things of the physical world are not exhausted in their mere facticity, in their crude reality, but they have an intelligibility: a sense that is manifested in that its function is not arbitrary or casual, but is intrinsically oriented towards the achievement of a purpose. The teleological view of the world considers that physical things are not formless fragments of matter, but are endowed with a nature, so they are subject to their own actions that are directed towards their own end, i.e. natural. The trivialisation of finalism, its simplistic presentation as a physical explanation, earned rejection by modern mechanicism on the charge of anthropomorphism, that is, of attributing some kind of intentions that only man can have to physical or biological activities. But none of that suggests the teleological concept; particularly because it is not a theory to provide 
specific physical explanations, but a metaphysical concept of the world and man for whom all reality is intelligible and is endowed with meaning, even though we do not always know precisely what that nature is that gives each thing its own purpose.

The rejection of teleology by modern mechanicism has already seen its historical exhaustion. The teleological concept of nature allows us to understand the emergence of the new as an update of potentialities ordered to an end. Unlike mechanicism, the teleological concept of nature does not understand physical reality as an undifferentiated fabric, but as a differentiated order, with a single sense and purpose that is given by a transcendent intelligence. Only thus from a metaphysical concept of evolutionary creation can the meaning of biological evolution be understood. ${ }^{38}$

An unquestionably important biological question is whether human beings, as a result of biological evolution, are the product of chance or of purpose in the evolutionary process. This double possibility raises an objective metaphysical problem: is there teleology or teleonomy in biological evolution? In the first case, nature, following the laws of evolution, directs the development of living beings until the emergence of Homo sapiens. In the second case, an intelligence external to the evolutionary process somehow directed it or, at least, caused living organisms to have a self-regulation program that directs their development to a specific end.

Overall, compelling evidence suggests that biological evolution develops according to an end, and consequently, that there must be a higher intelligence that somehow programs this evolutionary process.

38. Alejandro Llano, "Evolución y creación, en los confines del conocimiento," in Carlos Marmelada, Emilio Palafox, and Alejandro Llano, En busca de nuestros orígenes: Biología y transcendencia del hombre a la luz de los últimos descubrimientos (Madrid: Ediciones Rialp, 2017), 29-41. 
